\title{
Percentage of energy contribution according to the degree of industrial food processing and associated factors in adolescents (EVA-JF study, Brazil)
}

\author{
Adriana ST Melo ${ }^{1,2, *}$ (1), Felipe S Neves ${ }^{1,2}$ (1) Aline P Batista $^{3}$, \\ George Luiz L Machado-Coelho ${ }^{3}$, Daniela S Sartorelli ${ }^{4}\left(\mathbb{C}\right.$, Eliane R de Faria ${ }^{2}$, \\ Michele P Netto ${ }^{1,2}$, Renata MS Oliveira ${ }^{1,2}$, Vanessa S Fontes ${ }^{1,2}$ and \\ Ana Paula C Cândido ${ }^{1,2}$ (1) \\ 'Postgraduate Program in Public Health, School of Medicine, Federal University of Juiz de Fora (UFJF), Juiz de Fora, \\ MG, Brazil: "2Department of Nutrition, Institute of Biological Sciences, Federal University of Juiz de Fora (UFJF), José \\ Lourenço Kelmer St, Campus Universitário, São Pedro, Juiz de Fora, MG 36036-900, Brazil: ${ }^{3}$ Laboratory of \\ Epidemiology, School of Medicine, Federal University of Ouro Preto (UFOP), Ouro Preto, MG, Brazil: ${ }^{4}$ Department of \\ Social Medicine, School of Medicine, University of São Paulo (USP), Ribeirão Preto, SP, Brazil
}

Submitted 4 July 2020: Final revision received 20 December 2020: Accepted 5 January 2021: First published online 13 January 2021

\begin{abstract}
Objective: To evaluate energetic contribution according to the degree of industrial food processing and its association with sociodemographic, anthropometric, biochemical, clinical and behavioural characteristics in adolescents.

Design: Cross-sectional study (Adolescent Lifestyle Study). Food consumption was assessed using 24-h dietary recalls, with foods classified by degree of industrial progressing. The usual diet was estimated using the Multiple Source Method. In a linear regression model, the energy percentage (E \%) was associated with sociodemographic, anthropometric, biochemical, clinical and behavioural characteristics, after adjustment for sex and age.

Setting: Juiz de Fora, Brazil.

Participants: Eight hundred and four adolescents, of both sexes, 14-19 years of age, enrolled in public schools.

Results: The E \% of unprocessed or minimally processed foods corresponded to $43.1 \%$, processed foods to $11.0 \%$ and the ultraprocessed foods to $45.9 \%$. E \% of unprocessed foods was associated with socio-economic stratum (adjusted $\beta=-0.093 ; P=0.032$ ), neck circumference (adjusted $\beta=0.017 ; P=0.049$ ), screen time (adjusted $\beta=-0.247 ; P=0.036$ ) and HDL-cholesterol (adjusted $\beta=-0.156$; $P=0.003)$. E \% of ultraprocessed foods was associated with socio-economic stratum (adjusted $\beta=0.118 ; P=0.011$ ), screen time (adjusted $\beta=0.375 ; P=0.003$ ), BMI (adjusted $\beta=-0.029 ; P=0.025$ ), neck circumference (adjusted $\beta=-0.017$; $P=0.028$ ) and HDL-cholesterol (adjusted $\beta=0.150 ; P=0.002$ ).

Conclusions: There was a high $\mathrm{E} \%$ of ultraprocessed foods in the diet of the adolescents. Actions are needed to raise the awareness of adopting healthy eating habits.
\end{abstract}



In the NOVA food classification system, items are grouped according to the nature, purpose and degree of industrial processing, comprising four groups: unprocessed or minimally processed foods (e.g. rice, meat, fruits and vegetables), processed culinary ingredients (e.g. salt, sugar, and oils and fat), processed foods (e.g. bread and cheese) and ultraprocessed foods (e.g. soft drinks, ready frozen food and candies), the latter being rich in sugars, fats, $\mathrm{Na}$, and low in fibre, micronutrients and proteins ${ }^{(8)}$. 
Adolescence is a phase characterised by several biopsychosocial and behavioural changes, thus becoming a period in which adolescents may be more vulnerable to the presence of risky behaviours which have health implications, such as the emergence of non-communicable diseases $^{(\vartheta, 10)}$.

Studies conducted with adolescents have shown that ultraprocessed food consumption was associated with family income and parents' education level ${ }^{(6,11,12)}$; physical inactivity ${ }^{(13)}$; sedentary behaviour, especially in individuals with high screen time ${ }^{(14)}$; culminating in excess of weight $^{(15-18)}$, metabolic ${ }^{(19)}$ and blood pressure alterations ${ }^{(20)}$. Although diseases appear mainly in adulthood, their precursors can still be present during childhood and adolescence $^{(21,22)}$.

Considering the ongoing increase in the energy percentage $(\mathrm{E} \%)$ of the diet from ultraprocessed foods ${ }^{(1-3,23)}$ and its implications for health ${ }^{(18,24)}$, this study contributes to the existing literature, showing the association with sociodemographic, anthropometric, biochemical, clinical and behavioural characteristics, in contrast to other studies that work with these variables separately ${ }^{(11,14,20,25-27)}$. This study is relevant because it contributes effective strategies for promoting healthy eating habits in adolescence and is also important because it deals with the different realities of the Brazilian population, since Brazil is a country with continental dimensions.

Thus, the aim of this study was to evaluate the energetic contribution according to the degree of industrial food processing and its association with sociodemographic, anthropometric, biochemical, clinical and behavioural characteristics in Brazilian adolescents.

\section{Methods}

\section{Data source, population and sampling}

This is a cross-sectional study based on data from the Adolescent Lifestyle Study (Portuguese acronym EVA-JF Study), a representative survey of adolescents from public schools in Juiz de Fora, Minas Gerais, Brazil.

The study included adolescents, aged 14-19 years, of both sexes, regularly enrolled in schools located in the urban area of the municipality. The sample calculation ( $n$ 790) was performed based on the number of students enrolled in basic education in the years 2018 and 2019, referring to the morning classes of the 9th grade of elementary school and 1st, 2nd and 3rd year of high school, according to the Brazilian educational system, and the prevalence of obesity among adolescents of $8.0 \%(10,28,29)$, accuracy around $2.0 \%$ of prevalence, SE of $1.0 \%$, CI of $95 \%$ and subject loss of $20 \%$. The participants were 835 adolescents. Considering the lack of information about food consumption data, the final sample consisted of 804 adolescents.
The selection of participants was carried out at random, stratified and proportional by administrative regions, schools, school years, classes and sex. Data collection was carried out by a team trained at the educational institutions themselves, in the morning, from May 2018 to May 2019. Further details on the sampling, selection of participants and methodology can be obtained in Neves et al. ${ }^{(30)}$.

\section{Food consumption and classification}

Food consumption data were obtained by applying two 24-h dietary recalls, with an interval of approximately 1 week, on alternate weekdays. Both recalls were applied in person by trained researchers using the multiple-pass method ${ }^{(31)}$. A food photo manual containing examples of portion sizes, serving utensils and household measures was used, helping to estimate the quantities consumed, as well as providing more accurate information on food consumption ${ }^{(32)}$.

Energy intake (kcal) was estimated using a table of food consumption $^{(33)}$ and nutritional labels, when necessary, with foods classified according to the extent and purpose of industrial processing, according to the NOVA food classification system, proposed by Monteiro et al. ${ }^{(34,35)}$. Foods were divided into three groups: (a) unprocessed or minimally processed foods, culinary ingredients and preparations based on these foods (e.g. rice, beans, fruits, milk, salt and oils); (b) processed foods (e.g. breads and processed cheeses) and (c) ultraprocessed foods (e.g. soft drinks, salted crackers, filled cookies, sweeties, frozen foods). Culinary ingredients were clustered with unprocessed or minimally processed foods, since they are rarely used in isolation, but generally used in culinary preparations. In addition, all reported culinary preparations had their respective foods listed and later classified into the groups to which they belonged. Supplement 1 presents the main foods and/or food groups consumed by adolescents in the study.

Subsequently, the usual diet was estimated using the Multiple Source Method version 1.0.1 (German Department of Epidemiology of the Potsdam-Rehbrücke Institute of Human Nutrition, Germany), which can estimate the usual intake of each individual by means of adjustment based on 24-h dietary recalls, attenuating the intra-individual variance. The outcome variable was described using the energy percentage ( $\mathrm{E} \%$ ) of each food group.

\section{Sociodemographic and anthropometric variables}

Information about age, sex, skin colour and educational level of the legal guardians was obtained through interviews using structured questionnaires. The socio-economic status was verified using the Brazilian Criterion of Economic Classification ${ }^{(36)}$, defining the economic classes at $\mathrm{A} 1, \mathrm{~A} 2, \mathrm{~B} 1, \mathrm{~B} 2, \mathrm{C} 1, \mathrm{C} 2, \mathrm{D}$ and $\mathrm{E}$, in decreasing order of purchasing power.

For anthropometric analysis, weight and body fat were measured using a bipolar bioelectrical impedance scale 
(Tanita Ironman ${ }^{\circledR}$, model BC-553, Tanita Corp.), with participants standing upright in the centre of platform, barefoot and wearing light clothing ${ }^{(37)}$. Height was determined using a portable stadiometer (Alturexata ${ }^{\circledR}$ ), with participants with their backs to the marker, in an upright position, barefoot and with their feet joined at the ankles ${ }^{(37)}$. The BMI-for-age was defined by the $Z$-score, according to the $\mathrm{WHO}^{(38)}$ criteria. Neck circumference was measured using an inelastic tape (Sanny ${ }^{\circledR}$, American Medical Ltda), in the middle cervical spine and the mid-anterior region, perpendicular to the longitudinal axis, at the level below the laryngeal prominence ${ }^{(39)}$. Waist circumference was measured midway between the lowest rib and the iliac crest with inelastic tape ${ }^{(40,41)}$.

\section{Biochemical, clinical and behavioural variables}

For the evaluation of biochemical parameters, blood samples were collected after fasting for 8-12 h to measure total cholesterol, cholesterol associated with HDL, cholesterol associated with LDL and TAG, using the reference values of the Brazilian Society of Cardiology ${ }^{(42,43)}$ by age group, and fasting blood glucose, classified according to the criteria established by the American Diabetes Association ${ }^{(44)}$, also according to age.

Blood pressure levels were measured using a digital oscillometric device (Omron ${ }^{\circledR} 705$-IT, Omron Healthcare Inc.) with an adjustable cuff for the perimeter of the arm. The values of systolic blood pressure and diastolic blood pressure were classified by percentiles according to sex, age and height, according to the recommendations of the Brazilian Society of Cardiology ${ }^{(45)}$, and for those between 18 and 19 years of age, the classifications recommended for adults were used ${ }^{(46)}$.

The practice of physical activity in the last 12 months was assessed using a questionnaire, in which the type of exercise, frequency and time spent in a regular week were reported $^{(47,48)}$. Participants who reported practicing $\geq 420 \mathrm{~min} /$ week were classified as physically active ${ }^{(49)}$. Furthermore, information was obtained regarding screen time (watching movies, soap operas, playing video games, and using a smartphone, tablet or computer); the information was obtained using the cut-off point of the American Academy of Pediatrics ${ }^{(50)}$, which recommends $2 \mathrm{~h}$ as the maximum daily limit.

\section{Statistical analysis}

For statistical analysis, the normality of continuous variables was initially verified using the Kolmogorov-Smirnov test. The sociodemographic, anthropometric, biochemical, clinical and behavioural characteristics of the sample were described using measures of central tendency (mean and SD). For quantitative variables, absolute and relative frequencies (percentages and absolute numbers) were used.

An analysis was performed using linear regression models adjusted between the $\mathrm{E} \%$ from the consumption of each food group, according to NOVA, and the sociodemographic, anthropometric, biochemical, clinical and behavioural variables. The level of education of the legal guardians was described by years of study, and screen time and regular physical activity using the daily average (in minutes), including weekdays and weekends. For the analysis of the association between sociodemographic and behavioural variables, the $\mathrm{E} \%$ from the consumption of each food group was used as the dependent variable, whereas the analysis with anthropometric, biochemical and clinical variables, the $\mathrm{E} \%$ from the consumption of each food group was used as an independent variable. Subsequently, the analyses were adjusted for sex, age and skin colour. For all analyses, a $95 \%$ CI and a $5 \%$ significance level were taken into account. The data were analysed using the Statistical Package for the Social Sciences (SPSS) version 20.0 statistical software.

\section{Results}

\section{Population characteristics}

The sample consisted of 804 adolescents with a mean age of $16 \cdot 1 \pm 1 \cdot 2$ years. Females comprised $57.7 \%$ ( $n$ 462) of the evaluated students. Regarding skin colour, $62 \cdot 4 \%$ ( $n$ 497) declared themselves as black or brown and $46.9 \%$ ( $n$ 377) presented low income (including classes C1, C2, D-E) from the Brazilian Criterion of Economic Classification. Regarding maternal schooling, $75.2 \%$ ( $n$ 548) of the students reported that their mothers had more than 8 years of education.

Most of the sample showed normal weight (70.0\%, $n$ 561) and normal blood pressure levels ( $84.4 \%, n$ 677). The practice of regular physical activity in the last 12 months was reported by $55 \cdot 3 \%$ ( $n$ 445); however, only $16.5 \%$ ( $n$ 133) engaged in exercise for $\geq 420 \mathrm{~min} /$ week. Regarding sedentary behaviour, $91.8 \%$ ( $n$ 738) of the adolescents had a daily screen time of more than $2 \mathrm{~h}$. Table 1 shows the sociodemographic, anthropometric, biochemical, clinical and behavioural characteristics of the sample.

\section{Distribution of total energy by food group}

The average energetic intake of the sample was $8949.95 \pm$ 2005.39 kJ. Regarding the degree of industrial processing, the mean $\mathrm{E} \%$ of the contribution of unprocessed or minimally processed foods and preparations based on these foods was $43.1 \%(95 \%$ CI $42 \cdot 4,43 \cdot 8)$, of processed foods $11.0 \%(95 \%$ CI $10 \cdot 7,11 \cdot 3)$ and $45.9 \%$ (95\% CI 45.1, 46.7) for ultraprocessed foods.

\section{Associations of sociodemographic and behavioural variables with food consumption}

In linear regression models (Table 2), when comparing the $\mathrm{E} \%$ of contribution with sociodemographic and behavioural characteristics, a negative association was observed between the classification score of the socio-economic 
Table 1 Sociodemographic, anthropometric, biochemical, clinical and behavioural characteristics, EVA-JF study, Brazil, 2018-2019

\begin{tabular}{|c|c|c|c|}
\hline Variables & $n$ & Mean & SD \\
\hline \multicolumn{4}{|l|}{ Sociodemographic } \\
\hline Age (years) & 804 & $16 \cdot 1$ & 1.2 \\
\hline $\begin{array}{l}\text { Years of study of a male parent/legal } \\
\text { guardian }\end{array}$ & 612 & $10 \cdot 4$ & $3 \cdot 7$ \\
\hline $\begin{array}{l}\text { Years of study of a female parent/legal } \\
\text { guardian }\end{array}$ & 719 & $10 \cdot 7$ & $3 \cdot 6$ \\
\hline \multicolumn{4}{|l|}{ Anthropometrics } \\
\hline Weight (kg) & 802 & 61.7 & $13 \cdot 0$ \\
\hline Height $(\mathrm{cm})$ & 803 & $166 \cdot 3$ & 8.8 \\
\hline BMl for age $\left(\mathrm{kg} / \mathrm{m}^{2}\right)$ & 802 & $22 \cdot 2$ & $4 \cdot 2$ \\
\hline Neck circumference $(\mathrm{cm})$ & 803 & 33.6 & $3 \cdot 2$ \\
\hline Waist circumference $(\mathrm{cm})$ & 803 & 73.5 & 9.6 \\
\hline Body fat (\%) & 803 & 21.5 & $9 \cdot 6$ \\
\hline \multicolumn{4}{|l|}{ Biochemical and clinical } \\
\hline Total cholesterol (mg/dl) & 800 & $157 \cdot 5$ & 33.2 \\
\hline HDL-cholesterol (mg/dl) & 800 & 71.8 & $15 \cdot 9$ \\
\hline LDL-cholesterol (mg/dl) & 800 & 71.4 & $28 \cdot 5$ \\
\hline TAG (mg/dl) & 800 & $71 \cdot 7$ & $30 \cdot 2$ \\
\hline Fasting glucose $(\mathrm{mg} / \mathrm{dl})$ & 800 & $84 \cdot 7$ & $7 \cdot 3$ \\
\hline $\mathrm{SBP}(\mathrm{mmHg})$ & 802 & $107 \cdot 9$ & $12 \cdot 7$ \\
\hline $\mathrm{DBP}(\mathrm{mmHg})$ & 802 & $68 \cdot 7$ & $7 \cdot 4$ \\
\hline \multicolumn{4}{|l|}{ Behavioural } \\
\hline Screen time* $(h / d)$ & 804 & $6 \cdot 3$ & $3 \cdot 1$ \\
\hline Physical activity† ( $\mathrm{min} / \mathrm{d}$ ) & 445 & $339 \cdot 8$ & $266 \cdot 2$ \\
\hline
\end{tabular}

SBP, systolic blood pressure; DBP, diastolic blood pressure.

*Daily exposure time considering activities such as watching movies, soap operas, series, playing video games, and using smartphones, tablets or computers for other purposes.

†Regular practice of sports or physical exercise at home, on the street, at a square, park, club, gym or sports school considering the last 12 months.

stratum and unprocessed foods after adjustment for sex and skin colour (adjusted $\beta=-0.093 ; P=0.032$ ) and positive with ultraprocessed foods, with and without adjustments (crude $\beta=0.089 ; \quad P=0.047$; adjusted $\beta=0.118$; $P=0.011$ ), as well as screen time with all food groups, unprocessed or minimally processed foods, culinary ingredients and preparations based on these foods (crude $\beta=-0.233 ; P=0.047$; adjusted $\beta=-0.247 ; P=0.036)$, processed foods (crude $\beta=-0.114 ; P=0.025$; adjusted $\beta=-0.128 ; P=0.011$ ) and ultraprocessed foods (crude $\beta=0.347 ; P=0.006$; adjusted $\beta=0.375 ; P=0.003)$.

\section{Associations of antbropometric, biochemical and clinical variables with food consumption}

Regarding anthropometric characteristics (Table 3), a negative association was observed between BMI and consumption of ultraprocessed foods after adjustment for sex and age (adjusted $\beta=-0.029 ; \quad P=0.025$ ). Furthermore, there was a positive association between the neck circumference and the group of unprocessed or minimally processed foods, remaining significant after adjustment for sex and age (crude $\beta=0.023 ; P=0.034$; adjusted $\beta=0.017 ; P=0.049$ ), and a negative association with the consumption of ultraprocessed foods, in both models (crude $\quad \beta=-0.031 ; \quad P=0.002 ; \quad$ adjusted $\beta=-0.017 ; P=0.028)$. No association was found with the other anthropometric variables.
Regarding biochemical and clinical characteristics (Table 4), there was an inverse association between total cholesterol and unprocessed or minimally processed foods (crude $\beta=-0.262 ; P=0.019$ ) and a positive one with ultraprocessed foods (crude $\beta=0.228 ; P=0.029$ ). However, after adjustments, they did not remain significant. An association was also observed in the same directions between the HDL-cholesterol fraction with the same food groups, with and without adjustments, for unprocessed foods (crude $\quad \beta=-0.178 ; \quad P=0.001 ; \quad$ adjusted $\beta=-0.156$; $P=0.003$ ) and ultraprocessed foods (crude $\beta=0.175$; $P=0.000 ;$ adjusted $\beta=0.150 ; P=0.002)$.

\section{Discussion}

The results of the present study showed a high $\mathrm{E} \%$ of contribution from ultraprocessed foods. Furthermore, an association was observed between food consumption, according to the degree of industrial processing, and socio-economic stratum, screen time, BMI, neck circumference and serum HDL-cholesterol levels.

The E \% from ultraprocessed foods found in this study was similar to the one observed by D'ávila and Kirsten $^{(12)}$, in a Brazilian municipality, representing $49 \cdot 2 \%$ of the total daily energy value. Similarly, in another study conducted with adolescents in the Northeast of Brazil, a high $\mathrm{E} \%$ of contribution from this group of foods $(46 \cdot 2 \%)^{(26)}$ was also demonstrated. Therefore, a high intake of ultraprocessed foods is observed in this age group.

When evaluating the association between food consumption and sociodemographic characteristics, an inverse association was found between the socio-economic stratum and unprocessed foods, demonstrating a higher consumption of these foods among those with less purchasing power. In contrast, a positive association was found with the consumption of ultraprocessed foods, with a higher $\mathrm{E} \%$ of contribution of foods belonging to this group among those with a higher socio-economic stratum. A similar pattern was observed in a study conducted with Brazilian $^{(6)}$ and Chilean ${ }^{(51)}$ adolescents; young individuals living in urban areas and with higher income had a higher intake of ultraprocessed foods, although inverse associations were also found ${ }^{(12)}$

Several factors can influence food choices, such as physiological, behavioural, social and economic, among others. Unlike what we find in relation to income, there was no association between food consumption and education level of parents or guardians. Sociodemographic factors such as higher income and education allow better access to information and a more varied diet; however, this condition is not always related to adequate food choices $^{(6,52)}$. According to data from the Household Budget Survey (POF 2017-2018), carried out in Brazil, the total energetic intake of ultraprocessed foods in the diet 


\section{Public Health Nutrition}

Table 2 Linear regression models, association of food consumption according to degree of industrial processing and sociodemographic and behavioural characteristics, EVA-JF study, Brazil, 2018-2019

\begin{tabular}{|c|c|c|c|c|c|c|c|c|c|c|c|c|}
\hline & \multicolumn{4}{|c|}{ Unprocessed foods ${ }^{*}$} & \multicolumn{4}{|c|}{ Processed foods } & \multicolumn{4}{|c|}{ Ultraprocessed foods } \\
\hline & Crude $\beta$ & $95 \% \mathrm{Cl}$ & Adjusted $\beta$ & $95 \% \mathrm{Cl}$ & Crude $\beta$ & $95 \% \mathrm{Cl}$ & Adjusted $\beta$ & $95 \% \mathrm{Cl}$ & Crude $\beta$ & $95 \% \mathrm{Cl}$ & Adjusted $\beta$ & $95 \% \mathrm{Cl}$ \\
\hline Age (years) $\dagger$ & -0.451 & $-1 \cdot 06,0 \cdot 16$ & -0.469 & $-1.08,0.14$ & 0.178 & $-0.08,0.44$ & 0.161 & $-0.01,0.42$ & 0.273 & $-0.38,0.93$ & 0.308 & $-0.34,0.96$ \\
\hline Socio-economic stratum (score) $\ddagger, \S$ & -0.074 & $-0.16,0.01$ & -0.093 & $-0.18,-0.01$ & -0.016 & $-0.05,0.02$ & -0.025 & $-0.06,0.01$ & 0.089 & $0.00,0.18$ & 0.118 & $0.03,0.21$ \\
\hline Mother education level (years of study)\|,§ & -0.075 & $-0.29,0.14$ & -0.116 & $-0.33,0.10$ & -0.027 & $-0.12,0.07$ & -0.045 & $-0.14,0.05$ & 0.102 & $-0.12,0.33$ & 0.161 & $-0.07,0.39$ \\
\hline Father education level (years of study) $\rrbracket, \S$ & -0.071 & $-0.29,0.15$ & -0.103 & $-0.32,0.12$ & -0.033 & $-0.13,0.07$ & -0.040 & $-0.14,0.06$ & 0.104 & $-0.13,0.34$ & 0.143 & $-0.09,0.38$ \\
\hline Physical activity $(\mathrm{min})^{\star \star}, \dagger \dagger$ & 0.000 & $-0.00,0.00$ & -0.001 & $-0.00,0.00$ & 0.001 & $-0.00,0.00$ & -0.000 & $-0.00,0.00$ & -0.001 & $-0.00,0.00$ & -0.001 & $-0.00,0.00$ \\
\hline Screen time $(\mathrm{h}) \ddagger \ddagger, \dagger \dagger$ & -0.233 & $-0.46,-0.00$ & -0.247 & $-0.48,-0.02$ & -0.114 & $-0.21,-0.01$ & -0.128 & $-0.23,-0.03$ & 0.347 & $0.10,0.59$ & 0.375 & $0.13,0.62$ \\
\hline
\end{tabular}

*Or minimally processed, culinary ingredients and preparations based on these foods.

†Adjusted for sex.

¥Score obtained from the Brazilian Criterion of Economic Classification (BCEC).

${ }^{\$}$ Adjusted for sex and skin colour.

"Or female legal guardian.

${ }^{\star *}$ Time spent on sports or physical activities in a typical week.

††Adjusted for sex and age.

拉aily exposure time considering activities such as watching movies, soap operas, television shows, playing video games, and using smartphone, tablet or computer for other purposes. 
Table 3 Linear regression models, association of food consumption according to degree of industrial processing and anthropometric characteristics, EVA-JF study, Brazil, 2018-2019

\begin{tabular}{|c|c|c|c|c|c|c|c|c|c|c|c|c|c|}
\hline & & \multicolumn{2}{|c|}{ Weight $(\mathrm{kg})$} & \multicolumn{2}{|c|}{ Height $(\mathrm{cm})$} & \multicolumn{2}{|c|}{ BMI $\left(\mathrm{kg} / \mathrm{m}^{2}\right)$} & \multicolumn{2}{|c|}{ Body fat (\%) } & \multicolumn{2}{|c|}{$\begin{array}{l}\text { Neck circumference } \\
(\mathrm{cm})\end{array}$} & \multicolumn{2}{|c|}{$\begin{array}{l}\text { Waist circumference } \\
(\mathrm{cm})\end{array}$} \\
\hline & & $\beta$ & $95 \% \mathrm{Cl}$ & $\beta$ & $95 \% \mathrm{Cl}$ & $\beta$ & $95 \% \mathrm{Cl}$ & $\beta$ & $95 \% \mathrm{Cl}$ & $\beta$ & $95 \% \mathrm{Cl}$ & $\beta$ & $95 \% \mathrm{Cl}$ \\
\hline \multirow{2}{*}{ Unprocessed foods ${ }^{*}$} & Crude $\beta$ & 0.043 & $-0.04,0.13$ & -0.008 & $-0.07,0.05$ & 0.016 & $-0.01,0.04$ & 0.005 & $-0.06,0.07$ & 0.023 & $0.00,0.04$ & 0.027 & $-0.04,0.09$ \\
\hline & Adjusted $\beta \dagger$ & 0.038 & $-0.04,0.12$ & -0.034 & $-0.08,0.01$ & 0.022 & $-0.01,0.05$ & 0.036 & $-0.01,0.09$ & 0.017 & $0.00,0.03$ & 0.029 & $-0.03,0.09$ \\
\hline \multirow{2}{*}{ Processed foods } & Crude $\beta$ & 0.221 & $0.02,0.42$ & 0.086 & $-0.05,0.22$ & 0.059 & $-0.01,0.12$ & -0.079 & $-0.23,0.07$ & 0.068 & $0.02,0.12$ & 0.140 & $-0.01,0.29$ \\
\hline & Adjusted $\beta \dagger$ & 0.121 & $-0.07,0.31$ & -0.062 & $-0.16,0.04$ & 0.061 & $-0.00,0.13$ & 0.076 & $-0.04,0.19$ & 0.018 & $-0.02,0.06$ & 0.093 & $-0.05,0.24$ \\
\hline \multirow[t]{2}{*}{ Ultraprocessed foods } & Crude $\beta$ & -0.072 & $-0.15,0.01$ & -0.007 & $-0.06,0.05$ & -0.024 & $-0.05,0.00$ & 0.008 & $-0.05,0.07$ & -0.031 & $-0.05,-0.01$ & -0.046 & $-0.11,0.01$ \\
\hline & Adjusted $\beta \dagger$ & -0.053 & $-0.13,0.02$ & 0.040 & $-0.00,0.08$ & -0.029 & $-0.05,-0.00$ & -0.044 & $-0.09,0.00$ & -0.017 & $-0.03,-0.00$ & -0.040 & $-0.10,0.02$ \\
\hline
\end{tabular}

${ }^{*}$ Or minimally processed, culinary ingredients and preparations based on these foods.

†Adjusted for sex and age.

Table 4 Linear regression models, association of food consumption according to degree of industrial processing and biochemical and clinical characteristics, EVA-JF study, Brazil, 2018-2019

\begin{tabular}{|c|c|c|c|c|c|c|c|c|c|c|c|c|c|c|c|}
\hline & & \multicolumn{2}{|c|}{$\mathrm{TC}(\mathrm{mg} / \mathrm{dl})$} & \multicolumn{2}{|c|}{$\begin{array}{l}\text { LDL-cholesterol } \\
(\mathrm{mg} / \mathrm{dl})\end{array}$} & \multicolumn{2}{|c|}{$\begin{array}{l}\text { HDL-cholesterol } \\
(\mathrm{mg} / \mathrm{dl})\end{array}$} & \multicolumn{2}{|c|}{ TAG (mg/dl) } & \multicolumn{2}{|c|}{$\begin{array}{l}\text { Fasting glucose } \\
\qquad(\mathrm{mg} / \mathrm{dl})\end{array}$} & \multicolumn{2}{|c|}{$\mathrm{SBP}(\mathrm{mmHg})$} & \multicolumn{2}{|c|}{$\mathrm{DBP}(\mathrm{mmHg})$} \\
\hline & & $\beta$ & $95 \% \mathrm{Cl}$ & $\beta$ & $95 \% \mathrm{Cl}$ & $\beta$ & $95 \% \mathrm{Cl}$ & $\beta$ & $95 \% \mathrm{Cl}$ & $\beta$ & $95 \% \mathrm{Cl}$ & $\beta$ & $95 \% \mathrm{Cl}$ & $\beta$ & $95 \% \mathrm{Cl}$ \\
\hline \multirow{2}{*}{ Unprocessed foods* } & Crude $\beta$ & -0.262 & $-0.48,-0.04$ & -0.079 & $-0.27,0.11$ & -0.178 & $-0.28,-0.07$ & -0.026 & $-0.23,0.17$ & -0.009 & $-0.06,0.04$ & 0.064 & $-0.02,0.15$ & -0.018 & $-0.07,0.03$ \\
\hline & Adjusted $\beta \dagger$ & -0.206 & $-0.42,0.01$ & -0.048 & $-0.23,0.14$ & -0.156 & $-0.26,-0.06$ & -0.008 & $-0.21,0.19$ & -0.019 & $-0.07,0.03$ & 0.046 & $-0.03,0.12$ & -0.012 & $-0.06,0.04$ \\
\hline \multirow[t]{2}{*}{ Processed foods } & Crude $\beta$ & -0.008 & $-0.52,0.50$ & 0.150 & $-0.29,0.59$ & -0.131 & $-0.38,0.11$ & -0.134 & $-0.60,0.33$ & 0.048 & $-0.06,0.16$ & 0.210 & $0.02,0.40$ & 0.064 & $-0.05,0.18$ \\
\hline & Adjusted $\beta \dagger$ & 0.140 & $-0.36,0.64$ & 0.251 & $-0.18,0.69$ & -0.086 & $-0.33,0.16$ & -0.127 & $-0.59,0.34$ & 0.014 & $-0.10,0.12$ & 0.063 & $-0.11,0.24$ & 0.067 & $-0.05,0.18$ \\
\hline \multirow[t]{2}{*}{ Ultraprocessed foods } & Crude $\beta$ & 0.228 & $0.02,0.43$ & 0.044 & $-0.13,0.22$ & 0.175 & $0.08,0.27$ & 0.044 & $-0.14,0.23$ & 0.000 & $-0.05,0.05$ & -0.089 & $-0.17,-0.01$ & 0.005 & $-0.04,0.05$ \\
\hline & Adjusted $\beta \dagger$ & 0.157 & $-0.04,0.36$ & 0.022 & $-0.17,0.18$ & 0.150 & $0.06,0.25$ & 0.027 & $-0.16,0.21$ & 0.014 & $-0.03,0.06$ & -0.050 & $-0.12,0.02$ & -0.000 & $-0.05,0.05$ \\
\hline
\end{tabular}

TC, total cholesterol; SBP, systolic blood pressure; DBP, diastolic blood pressure.

*Or minimally processed, culinary ingredients and preparations based on these foods.

tAdjusted for sex and age. 
tended to increase with the increase in income, that is, families that had higher incomes, purchased twice the amount of ultraprocessed food compared to families with lower incomes $(24.7 \%$ of total energies $v .12 .5 \%$, respectively) ${ }^{(23)}$.

Sociocultural changes over the years have shown a decrease in the time spent on food preparation and the consequent increase in consumption of ultraprocessed foods. Some studies point out the lack of time due to work, family and other daily tasks as factors for such changes ${ }^{(53,54)}$. The present study investigates the food consumption of adolescents and potential negative influences on their consumption. Despite having autonomy over their own food choices, aspects related to family issues, such as the acquisition of food at home, the work situation of parents or guardians, the availability of time for preparing meals, among others, should be considered ${ }^{(55)}$.

The daily exposure time to screens was also associated with the degree of industrial food processing, showing an inverse correlation with the consumption of unprocessed or minimally processed foods and processed foods, and a positive correlation with the consumption of ultraprocessed foods. Data from the latest National Adolescent School-based Health Survey, carried out in 2009 and 2015, showed high prevalence of sedentary behaviour ( $79.5 \%$ and $68.1 \%$, respectively) among the evaluated students, with the latter showing that the higher the number of hours in front of screens, the higher the prevalence of daily consumption of ultraprocessed foods $(P<0 \cdot 001)^{(14,56)}$. This behaviour can be attributed to the greater practicality of consuming ultraprocessed foods, since they do not require preparation time and can be consumed while watching television, using tablets and playing video games. Furthermore, these means of communication are vehicles for advertisements and advertising campaigns that tend to favour inappropriate food consumption ${ }^{(57,58)}$.

Regarding anthropometric variables, only BMI and neck circumference were associated with food consumption by degree of industrial processing. There was a relationship between increase of unprocessed food consumption and the increase in these anthropometric parameters, and inverse relation with ultraprocessed food consumption. Although no association was found with weight and waist circumference, the same pattern of consumption can be observed. This inverse relationship of anthropometric parameters with ultraprocessed foods may have occurred due to the fact that the majority of the sample had appropriate weight. Unlike other studies that find inverse associations ${ }^{(17,59)}$, the higher consumption of unprocessed foods and less processed foods in the present study can be attributed to a possible change in eating behaviour due to the presence of overweight in these individuals, called reverse causality. However, due to the characteristic of the design of the present study, it will not be possible to confirm this relationship.
Associations with biochemical parameters were also found in this study. There was a negative correlation for unprocessed or minimally processed foods and preparations based on these foods with total cholesterol, and a positive correlation with ultraprocessed foods, so that the serum levels decreased as the percentage of contribution of the first group increased and were directly proportional to the ultraprocessed foods. Corroborating our findings, other studies have also found positive associations ${ }^{(60,61)}$. However, after adjustments for sex and age, they did not remain significant.

The same pattern was also observed with the HDLcholesterol fraction, showing associations with and without adjustments according to the degree of industrial processing. However, the results of this study differ from those found in other studies, in which the consumption of unprocessed foods favours the increase of HDL-cholesterol levels, while the consumption of ultraprocessed foods favours its reduction, the latter being a risk factor for the development of CVD in adulthood ${ }^{(60,62,63)}$. Only one study carried out in India, with women over 35 years old, also found a positive association between dietary pattern composed of saturated, hydrogenated fats, sweet condiments, fish and refined grains and serum levels of HDL-cholesterol ${ }^{(64)}$. The authors relate the finding to the greater presence of fats and lower carbohydrate content in this pattern, which may have favoured the increase in HDL-cholesterol.

In our sample, $97 \%$ of adolescents presented adequate HDL-cholesterol levels and high mean values, different from other studies, where lower prevalence of adequate HDLcholesterol levels was observed, such as in the Study of Cardiovascular Risks in Adolescents (ERICA), in 53.2\% of the sample $\mathrm{e}^{(65)}$ and in the study carried out by Martins et $a l{ }^{(27)}$, in which $47.7 \%$ of those evaluated had adequate serum HDL-cholesterol levels. A possible explanation for the association we found is that with an increase in the consumption of ultraprocessed foods, there is an increase in serum HDL-cholesterol levels, to a level similar to adolescents with lower consumption of ultraprocessed foods.

Another finding that draws attention in the study was the negative association between systolic blood pressure and consumption of ultraprocessed foods. However, after adjusting the model, it did not remain significant. Other studies carried out with children and adolescents show that the Western pattern, with the presence of processed foods, ready-made foods, sugary drinks, as they have high amounts of $\mathrm{Na}$ and energies from simple fats and carbohydrates, and low in proteins and fibres, favour the elevations in blood pressure levels ${ }^{(66,67)}$. As it is a chronic change, changes in blood pressure levels may not yet exist in our population.

The study has some limitations. The use of only two 24-h recalls, both performed on weekdays, may not represent the individuals' usual intake. However, the inclusion of a third recall was not possible and to minimise this existing 
intrapersonal variation, correction was then used, using the Multiple Source Method. Another limitation is that the sample is only representative of adolescents from public schools, which impedes generalising the results to Brazilian adolescents from private schools of the same age group. The cross-sectional study design may not be a limitation, since it does not allow inferences about causality; however, it helps in generating hypotheses about the causes of health problems. The study was carried out with a poorly studied population and with a representative sample and sought to analyse the relationship between the consumption of food according to its processing and several variables, which can contribute in the implementation of preventive interventions and the promotion of healthy habits in adolescence.

\section{Conclusions}

The present study found that in the diet of adolescents in Brazilian public schools, the $\mathrm{E} \%$ contribution of ultraprocessed foods is high. Moreover, associations were found between socio-economic stratum, screen time, BMI, neck circumference and serum HDL-cholesterol levels and food consumption according to the degree of industrial food processing. Therefore, the importance is highlighted for food and nutrition education activities in the school environment to guide appropriate food choices, together with effective public policies that promote actions and interventions that make this age group aware of adopting healthy lifestyle habits, such as engaging in regular physical activity and reducing screen time. In addition, changes in food labels, making them clearer and more understandable to the population, as well as the implementation of strict inspection policies on ultraprocessed foods, are necessary and urgent measures.

\section{Acknowledgements}

Acknowledgements: The authors would like to thank the Minas Gerais Research Foundation - FAPEMIG and Coordination for the Improvement of Higher Education Personnel - CAPES for the financial support and granting of scholarships, to the master's students involved in the operationalisation of data collection, to the technicians responsible for the Nutritional Surveillance and Assessment Laboratory and the Experimental Nutrition Laboratory of UFJF, to the scholarship students and volunteers, who were present in the field, the schools and the students who participated in the research. Financial support: This work was supported by the Minas Gerais Research Foundation - FAPEMIG (grant number for R.M.S.O.: APQ-02891-18; grant number for G.L.L.M.-C.: APQ-02643-15; and doctoral scholarship for F.S.N.);
Coordination for the Improvement of Higher Education Personnel - CAPES (doctoral scholarship for V.S.F. and master's scholarship for A.S.T.M.). Funders FAPEMIG and CAPES did not participate in the preparation, analysis or writing of this article. Conflict of interest: The authors have no conflicts of interest. Authorship: A.S.T.M. performed the statistical analysis and wrote the manuscript with contributions from all authors. A.P.B. and G.L.L.M.C. performed biochemical analyses. D.S.S. helped to estimate food consumption. F.S.N., E.R.F., M.P.N. and R.M.S.O. participated in the conception and design of this work and data analysis, as well as in the writing of the manuscript. V.S.F. conceived and designed the cross-sectional study and revised the article. A.P.C.C. conceived and designed the crosssectional study, coordinated the project and revised the paper. All authors contributed critically to the discussion and interpretation of the data, reviewed and approved the final manuscript. Ethics of buman subjectparticipation: This study was conducted according to the guidelines established in the Declaration of Helsinki, and all procedures involving research participants were approved by the Human Research Ethics Committee of the Federal University of Juiz de Fora, under protocol number 3.412.539 (CAAE: 68601617.1.0000.5147). Written informed consent was obtained from all participants.

\section{Supplementary material}

For supplementary material accompanying this paper visit https://doi.org/10.1017/S1368980021000100

\section{References}

1. Monteiro CA, Moubarac JC, Cannon G et al. (2013) Ultraprocessed products are becoming dominant in the global food system. Obes Rev 14, Suppl. 2, 21-28.

2. Pan American Health Organization - PAHO \& World Health Organization - WHO (2015) Ultra-Processed Food and Drink Products in Latin America: Trends, Impact on Obesity, Policy Implications. Washington, DC: PAHO.

3. Martins AP, Levy RB, Claro RM et al. (2013) Increased contribution of ultra-processed food products in the Brazilian diet (1987-2009). Rev Saúde Pública 47, 656-665.

4. Louzada ML, Martins AP, Canella DS et al. (2015) Ultraprocessed foods and the nutritional dietary profile in Brazil. Rev Saúde Pública 49, 1-11.

5. Moreno LA, Gottrand F, Huybrechts I et al. (2014) Nutrition and lifestyle in European adolescents: the HELENA (Healthy Lifestyle in Europe by Nutrition in Adolescence) Study. $A d v$ Nutr 5, 615S-623S.

6. Enes CC, Camargo CM \& Justino MI (2019) Ultra-processed food consumption and obesity in adolescents. Rev Nutr 32, e180170.

7. Neri D, Martinez-Steele E, Monteiro CA et al. (2019) Consumption of ultra-processed foods and its association with added sugar content in the diets of US children, NHANES 2009-2014. Pediatr Obes 14, e12563. 
8. Kelly B \& Jacoby E (2018) Public Health Nutrition special issue on ultra-processed foods. Public Health Nutr 21, 1-4.

9. World Health Organization (2012) Social Determinants of Health and Well-Being among Young People. Health Behaviour in School-Aged Children (HBSC) Study: International Report from the 2009/2010 Survey. Copenhagen: WHO Regional Office for Europe (Health Policy for Children and Adolescents, No. 6).

10. Brasil, Ministério do Planejamento, Orçamento e Gestão (2016) National School Health Survey (PeNSE), 2015. Rio de Janeiro (RJ): IBGE.

11. Maia EG, Silva LE, Santos MA et al. (2018) Dietary patterns, sociodemographic and behavioural characteristics among Brazilian adolescents. Rev Bras Epidemiol 21, Suppl. 1, E180009.

12. D'ávila HF \& Kirsten VR (2017) Energy intake from ultraprocessed foods among adolescentes. Rev Paul Pediatr 35, 54-60.

13. Souza JG, Lima LR, Fernandes CR et al. (2019) Physical activity and eating habits of adolescent students: National School Health Survey (PeNSE), 2015. Rev Bras Nutr Esp 13, 87-93.

14. Costa CS, Flores TR, Wendt A et al. (2018) Sedentary behavior and consumption of ultra-processed foods by Brazilian adolescents: Brazilian National School Health Survey (PeNSE), 2015. Cad Saúde Pública 34, e00021017.

15. Canella DS, Levy RB, Martins AP et al. (2014) Ultra-processed food products and obesity in Brazilian households (20082009). PLOS ONE 9, e92752.

16. Costa CS, Del-Ponte B, Assunção MC et al. (2018) Consumption of ultra-processed foods and body fat during childhood and adolescence: a systematic review. Public Health Nutr 21, 148-159.

17. Louzada ML, Baraldi LG, Steele EM et al. (2015) Consumption of ultra-processed foods and obesity in Brazilian adolescents and adults. Prev Med 81, 9-15.

18. Askari M, Heshmati J, Shahinfar H et al. (2020) Ultraprocessed food and the risk of overweight and obesity: a systematic review and meta-analysis of observational studies. Int J Obes 44, 2080-2091.

19. Tavares L, Fonseca S, Garcia Rosa M et al. (2012) Relationship between ultra-processed foods and metabolic syndrome in adolescents from a Brazilian Family Doctor Program. Public Health Nutr 15, 82-87.

20. Payab M, Roya K, Mostafa Q et al. (2015) Association of junk food consumption with high blood pressure and obesity in Iranian children and adolescents: the CASPIAN-IV Study. J Pediatr 91, 196-205.

21. Schommer VA, Barbiero SM, Cesa CC et al. (2014) Excess weight, anthropometric variables and blood pressure in schoolchildren aged 10 to 18 years. Arq Bras Cardiol 102, 312-318.

22. Enes CC \& Silva JR (2018) Association between excess weight and serum lipid alterations in adolescents. Ciênc Saúde Colet 23, 4055-4063.

23. Brasil, Ministério do Planejamento, Orçamento e Gestão (2020) Household Budget Survey - 2017-2018: Nutritional Assessment of Household Food Availability in Brazil. Rio de Janeiro (RJ): IBGE.

24. Chen X, Zhang Z, Yang H et al. (2020) Consumption of ultraprocessed foods and health outcomes: a systematic review of epidemiological studies. Nutr J 19, 86.

25. Martins HD, Jarret KV \& Crawley HF (2019) Eating meals with parents is associated with better quality of diet for Brazilian adolescentes. Cad Saúde Publica 35, e00153918.

26. Melo IS, Costa CA, Santos JV et al. (2017) Consumption of minimally processed food is inversely associated with excess weight in adolescents living in an underdeveloped city. PLOS ONE 12, e0188401.
27. Martins RV, Watanabe PI, Silva MP et al. (2018) Sexual maturation, physical activity and food consumption: association with the components of metabolic syndrome in adolescents. Adolesc Saúde 15, 16-26.

28. Bloch KV, Klein CH, Szklo M et al. (2016) ERICA: prevalences of hypertension and obesity in Brazilian adolescents. Rev Saúde Pública 50, 9s.

29. Brasil, Ministério do Planejamento, Orçamento e Gestão (2010) Household Budget Survey - 2008-2009. Anthropometry and Analysis of the Nutritional Status of Children and Adolescents in Brazil. Rio de Janeiro (RJ): IBGE.

30. Neves FS, Fontes VS, Pereira PM et al. (2019) EVA-JF study: methodological aspects, general sample characteristics, and potentialities of a study on the lifestyle of Brazilian adolescents. Adolesc Saúde 16, 113-129.

31. Conway JM, Ingwersen LA, Vinyard BT et al. (2003) Effectiveness of the US Department of Agriculture 5-step multiple-pass method in assessing food intake in obese and nonobese women. Am J Clin Nutr 77, 1171-1178.

32. Zaboto CB (1996) Photographic Record for Dietary Surveys: Utensils and Servings. Campinas: UNICAMP.

33. Brasil, Ministério do Planejamento, Orçamento e Gestão (2011) Household Budget Survey - 2008-2009. Table of Nutritional Composition of Foods Consumed in Brazil. Rio de Janeiro (RJ): IBGE.

34. Monteiro CA, Cannon G, Levy RB et al. (2019) Ultraprocessed foods: what they are and how to identify them. Public Health Nutr 22, 936-941.

35. Monteiro CA, Cannon G, Lawrence, M et al. (2019) UltraProcessed Foods, Diet Quality, and Health Using the NOVA Classification System. Rome: FAO.

36. Brazilian Association of Research Companies (2015) Brazilian Criterion of Economic Classification. http://www. abep.org (accessed October 2019).

37. Lohman TG, Roche AF \& Martorell R (1988) Anthropometric Standardization Reference Manual. Champaign, IL: Human Kinetics Books.

38. de Onis M, Onyango AW, Borghi E et al. (2007) Development of a WHO growth reference for school-aged children and adolescents. Bull World Health Organ 85, 660-667.

39. Ben-Noun L \& Laor A (2003) Relationship of neck circumference to cardiovascular risk factors. Obes Rev 11, 226-231.

40. McCarthy HD, Jarret KV \& Crawley HF (2001) The development of waist circumference percentiles in British children aged 5.0-16.9 year. Eur J Clin Nutr 55, 902-907.

41. World Health Organization (2008) Waist circumference and waist-hip ratio. Report of a WHO Expert Consultation. Geneva: WHO

42. Simão AF, Precoma DB, Andrade JP et al. (2013) Brazilian society of cardiology. I cardiovascular prevention guideline. Arq Bras Cardiol 101, Suppl. 2, 1-63.

43. Faludi AA, Izar MC, Saraiva JF et al. (2017) Update of the Brazilian guideline of dyslipidemia and atherosclerosis prevention - 2017. Arq Bras Cardiol 109, Suppl. 1, 1-76.

44. American Diabetes Association (2015) Classification and diagnosis of diabetes. Diabetes Care 38, Suppl. 1, S8-S16.

45. Malachias MV, Souza WK, Plavnik FL et al. (2016) 7th Brazilian guideline of arterial hypertension: chapter $10-$ Hypertension in children and adolescents. Arq Bras Cardiol 107, Suppl. 3, 53-63.

46. Malachias MV, Souza WK, Plavnik FL et al. (2016) 7th Brazilian guideline of arterial hypertension: chapter 2 - Diagnosis and classification. Arq Bras Cardiol 107, Suppl. 3, 7-13.

47. Matsudo S, Araújo T, Matsudo V et al. (2001) International physical activity questionnaire (IPAQ): study of validity and reliability in Brazil. Rev Bras Ativ Fis Saúde 6, 5-18.

48. Guedes DP, Lopes CC, Guedes JE (2005) Reproducibility and validity of the International Physical Activity Questionnaire in adolescents. Rev Bras Med Esporte 11, 151-158. 
49. World Health Organization (2010) Global Recommendations on Physical Activity for Health. Geneva: WHO.

50. Council on Communications and Media (2013) Children, adolescents, and the media. Pediatrics 132, 958-961.

51. Cediel G, Reyes M, Louzada ML et al. (2018) Ultra-processed foods and added sugars in the Chilean diet (2010). Public Health Nutr 21, 125-133.

52. Leal MA, Paiva SS, Sousa SS et al. (2019) Sociodemographic and behavioural factors associated with overweight in Brazilian adolescents - 2015. Adolesc Saúde 16, 16-26.

53. World Health Organization (2002) The World Report 2002: Reducing Ricks, Promoting Health Life. Geneva: WHO.

54. Campos KR (2004) Slow food movement: a criticism of the fast-food lifestyle. https://bdm.unb.br/bitstream/10483/ 393/1/2004_KarlaRamosCampos.pdf (accessed May 2020).

55. Villa JK, Silva AR, Santos TS et al. (2015) Dietary patterns of children and socioeconomical, behavioural and maternal determinants. Rev Paul Pediatr 33, 302-309.

56. Malta DC, Sardinha LM, Mendes I et al. (2010) Prevalence of risk health behavior among adolescents: results from the 2009 National Adolescent School-based Health Survey (PeNSE). Ciênc Saúde Colet 15, Suppl. 2, 3009-3019.

57. Mallarino C, Gómez LF, González-Zapata L et al. (2013) Advertising of ultra-processed foods and beverages: children as a vulnerable population. Rev Saúde Pública 47, 1006-1010.

58. Monteiro CA, Cannon G, Moubarac JC et al. (2018) The UN Decade of Nutrition, the NOVA food classification and the trouble with ultra-processing. Public Health Nutr 21, $5-17$.
59. Juul F, Martinez-Steele E, Parekh N et al. (2018) Ultraprocessed food consumption and excess weight among US adults. Br J Nutr 120, 90-100.

60. Dishchekenian VR, Escrivão MA, Palma D et al. (2011) Dietary patterns of obese adolescents and different metabolic effects. Rev Nutr 24, 17-29.

61. Ferreira FC, Vasconcelos SM, Santos EA et al. (2019) Evaluation of consumption of food and predictors of cardiovascular risk in hypertensive protectors of the State of Alagoas, Brazil. Ciênc Saúde Colet 24, 2419-2430.

62. Ambrosini GL, Huang RC, Mori TA et al. (2010) Dietary patterns and markers for the metabolic syndrome in Australian adolescents. Nutr Metab Cardiovasc Dis 20, 274-283.

63. Cunha CM, Costa PR, Oliveira LP et al. (2018) Dietary patterns and cardiometabolic risk factors among adolescents: systematic review and meta-analysis. $\mathrm{Br} J \mathrm{Nutr}$ 119, 859-879.

64. Ganguli D, Das N, Saha I et al. (2011) Major dietary patterns and their associations with cardiovascular risk factors among women in West Bengal, India. Br J Nutr 105, 1520-1529.

65. Neto-Faria JR, Bento VF, Baena CP et al. (2016) ERICA: prevalence of dyslipidemia in Brazilian adolescents. Rev Saúde Pública 50, Suppl. 1, 1-10.

66 Shang X, Li Y, Liu UMA et al. (2012) Dietary pattern and its association with the prevalence of obesity and related cardiometabolic risk factors among Chinese children. PLOS ONE 7, e43183.

67 Chen eu, Zhu H, Gutin B et al. (2019) Race, gender, family structure, socioeconomic status, dietary patterns, and cardiovascular health in adolescents. Curr Dev Nutr 3, nzz117. 